\title{
Parents Health and Social Life Matter for Self-Esteem of Child Orphans
}

\author{
Markos Abiso Erango, Ayele Taye Goshu* \\ School of Mathematical and Statistical Sciences, Hawassa University, Hawassa, Ethiopia \\ Email address: \\ markos.erango73@gmail.com (M. A. Erango),ayele_taye@yahoo.com (A. T. Goshu)
}

To cite this article:

Markos Abiso Erango, Ayele Taye Goshu. Parents Health and Social Life Matter for Self-Esteem of Child Orphans. Psychology and Behavioral Sciences. Vol. 4, No. 3, 2015, pp. 90-93. doi: 10.11648/j.pbs.20150403.11

\begin{abstract}
Orphaned children face several socio-economic challenges and psychological problems. They are exposed to low self-esteem that in turn leads to face difficulties of maintaining quality of life. This study is aimed to assess risk factors that may affect self-esteem status of orphans. A cross sectional study was conducted on orphans aged 5-18 years old at a local district Kacha-Birra, Southern Nations Nationalities and Peoples Regional State of Ethiopia. From a total of 3270 orphans in the district, 508 were selected using stratified random sampling technique. Data were collected with a designed questionnaire based on the Rosenberg's rating scales to measure their self-esteem levels. Self-esteem with a score less than or equal to average score was determined to be low. Binary logistic regression model was employed to analyze the data. The results of the study revealed that prevalence of low self-esteem among the child orphans was $57.3 \%$. Several risk factors were found to be significant at 5\% significance level. Increased risk to low self-esteem was due to: parent not living together before death, weak relationship between parents before death, low average monthly income, death of both parents, death due to AIDS, change in home circumstance for orphan, lack of love-care-support from care givers, stigma and discrimination. There are many orphans with low self-esteem in the study area. The factors negatively affecting self-esteem of the orphans mainly include the unhealthy social life of parents. Parents should be aware about the consequences of decisions they make about their health and social life on their children's future self-esteem.
\end{abstract}

Keywords: Child, Logistic Regression, Orphan, Self-Esteem

\section{Background}

Children are the hope of a country's future and so they should be well handled and educated. When orphaned, those need even more love, care and support as they often are exposed to several socio-economic and health challenges. The common reactions of a child to death of parent include: loneliness, low self-esteem, hopelessness, anger, confusion, helplessness, anxiety, depression and suicidal ideation [1]. Nyamukapa et el. [2] reported that orphans were found to suffer greater psychological distress than non-orphans, and reasons for increased levels of distress include trauma, being out-of-school, being cared for by a non-parent, inadequate care, child labour, physical abuse, and stigma and discrimination. Many studies reported that loss of one or both parents due to AIDS confronts the child with immense psychological and social problems that include stigmatization, discrimination, exploitation, emotional neglect and psychological distress [3 - 5].
Levine et al. [6] reported that factors affecting development of self-esteem include age, gender, socioeconomic status, body image, family relation, peer relations and social inequality. Baumeister et al. [7] stated that healthy self-esteem is strongly associated with happiness and confidence, while it is moderately related with academic performance. Unhealthy self-esteem may lead to poor academic achievement, physical and psychological outcomes including anxiety and depression.

The consequence for an orphan with low self-esteem is a poor quality of life, which deserves detailed investigations. Thus the main objective of this study was to assess selfesteem of the orphans in the study area and determine the associated risk factors.

\section{Methods}

The study population was 3270 orphans whom ages range 5-18 years old and residing in the local district Kacha-Birra in the Southern Nations, Nationalities and Peoples Regional 
State, Ethiopia. A cross sectional survey was conducted with a stratified random sampling technique on select 508 samples from the total population. The sample size 508 was determined with appropriate derivations. Data were collected using a designed questionnaire based on the Rosenberg's self-esteem scales that measure self-esteem levels of the respondents as in Rosenberg and Owens [8] and Rosendberg [9].

The response variable was an aggregate measure of selfesteem of an orphan. It is dichotomized as low self-esteem (coded as 1) if her/his test score was less than or equal to the average test score, and as high self-esteem (coded as 0 ) if the test score was greater than the average score, based on the Rosenberg's self-esteem scales.

The potential risk factors considered are: age of child, father's education, mother's education, father's occupation, mother's occupation, parents living together before death, strength of relationship between parents before death, average monthly income, deceased parents, cause of death if due to AIDS, change in home circumstance, housing ownership, residence of child, delivery of love-care-support by care givers, and stigma and discrimination.

\section{Logistic Regression Model}

The response variable is self-esteem status of an orphan, denoted by $Y$, which is dichotomous with outcome either low self-esteem (1) with probability $\mathrm{p}_{i}=\mathrm{P}\left(\mathrm{Y}_{i}=1 \mid \mathrm{X}_{\mathrm{i}}\right)$ or high self-esteem $(0)$ with probability $1-p_{i}=P\left(Y_{i}=0 \mid X_{i}\right)$, where $\mathrm{X}_{\mathrm{i}}$ is a vector of $r$ factors or predictors for each orphan $i=1,2,3, \ldots, n$.

The logistic regression model is given [10] as:

$$
p_{i}=\frac{e^{\beta_{0}+\beta_{1} X_{i 1}+\ldots+\beta_{r} X_{i r}}}{1+e^{\beta_{0}+\beta_{1} X_{i 1}+\ldots+\beta_{r} X_{i r}}}
$$

and equivalently expressed with the logit link function as:

$$
\operatorname{logit}\left(p_{i}\right)=\beta_{0}+\beta_{1} X_{i 1}+\ldots+\beta_{r} X_{i r}
$$

where $i=1,2,3, \ldots, n ; j=0,1,2,3, \ldots, r ; X_{i j}$ is the $j^{\text {th }}$ predictor of the $i^{\text {th }}$ child; $\beta_{0}$ is an intercept; $\beta_{j}$ 's are coefficients of the predictor variables.

\section{Estimation of the Parameters}

The likelihood function $L(y \mid X, \beta)$ is defined as the joint probability distribution $f(y \mid X, \beta)$ of the independent observation vector of size $n$ given the regression parameters $\beta$ and the design matrix $\mathrm{X}$. The likelihood function with the $n$ independent observations is expressed as:

$$
L(y \mid X, \beta)=\prod_{i=1}^{n}\left(\frac{e^{\beta_{0}+\beta_{1} x_{i 1}+\ldots+\beta_{x} x_{i r}}}{1+e^{\beta_{0}+\beta_{1} X_{11}+\ldots+\beta_{x} X_{i x}}}\right)^{y_{i}}\left(\frac{1}{1+e^{\beta_{0}+\beta_{1} x_{11}+\ldots+\beta_{x} X_{i x}}}\right)^{1-y_{i}}
$$

It refers to how likely a particular population is to produce an observed sample given the parameter values. Estimation of the parameters is based on the maximum likelihood method, with Newton-Raphson iterative search algorithm to maximize the likelihood function or its logarithmic transformation [10].

\section{Results and Discussion}

Among the samples considered, about $56.5 \%$ were females and the rest $43.5 \%$ were males. About $32.8 \%$ were in the age group $5-9,44.5 \%$ in age $10-14$, and $22.7 \%$ in age $15-18$ years old.

The analysis showed that the prevalence of low selfesteem among the orphans was $57.3 \%$. Only $42.7 \%$ of them were of high self-esteem. For $37.9 \%$ of the orphans, both parents deceased, mother only deceased for $20.2 \%$ and father only deceased for $41.9 \%$.About $19.4 \%$ of them knew that the cause for their parents' was AIDS.

Tests of association between the child's self-esteem status and the factors were carried out using the Chi-square tests. All the factors are significantly associated with the selfesteem status of a child at 5\% level of significance. The results are displayed in Table 1.
Table 1. Tests of Association of Predictor Variables with Self-esteem Status of the Orphans.

\begin{tabular}{llll}
\hline \multirow{2}{*}{\multicolumn{1}{c}{ Predictor Variable }} & \multicolumn{3}{c}{ Self-esteem Status } \\
\cline { 2 - 4 } & Chi-square & d.f. & P-value \\
\hline Age of child & 6.335 & 2 & .042 \\
Father's education level & 82.356 & 4 & .000 \\
Mother's education level & 33.775 & 4 & .000 \\
Occupation of father & 82.936 & 4 & .000 \\
Occupation of mother & 24.110 & 4 & .000 \\
Average monthly income & 222.381 & 4 & .000 \\
Parent living together before death & 194.306 & 2 & .000 \\
Strength of parents relationship before & 271.016 & 1 & .000 \\
death & 40.322 & 2 & .000 \\
Deceased parents & 52.420 & 1 & .000 \\
Cause of death due to AIDS & 163.615 & 1 & .000 \\
Change in home circumstance & 7.382 & 1 & .007 \\
Residence of child & 83.246 & 3 & .000 \\
Housing ownership (private,rented,other) & 17.509 & 1 & .000 \\
Love-care-support from care givers & 38.441 & 1 & .000 \\
Stigma and Discrimination & & & \\
\hline
\end{tabular}

For assessing the goodness-of-fit of the model, the Hosmer-Lemeshow test given by Hosmer and Lemeshow [11] was used. The Chi-square test statistic value was 3.783 with 8 degree of freedom at 0.876 significant levels. Hence, there was no enough evidence to reject the null hypothesis that the model fits the data. Moreover, the likelihood ratio test 
(deviance) was applied to test the difference between the null and the final model, with results of $-2 \operatorname{LogLiklihoodto~be}$ 690.00 for null model and 182.38 for the final model. The likelihood ratio testis 508.22 with 10 degree of freedom. Thus the final model with eight significant predictors was considered to be better than the null model.

Results of the logistic regression analysis are displayed in Table 2. The risk factors: number of parents died, cause of parent's death known to child is AIDS, average monthly income, delivery of love-care-support by care givers, stigma and discrimination, change in home circumstance, strength of relationship between parents, and whether or not parent were living together before death had significant effect on selfesteem of the orphans. The fitted model which can be used for predicting the probability of a randomly selected child to be in low self-esteem is given as:

$$
\operatorname{logit}\left(p_{i}\right)=3.525+\hat{\beta}_{\mathrm{NDP}} \mathrm{X}_{i 1}+\hat{\beta}_{\mathrm{CD}} \mathrm{X}_{i 2}+\hat{\beta}_{\mathrm{AI}} \mathrm{X}_{i 3}+\hat{\beta}_{\mathrm{LLS}} \mathrm{X}_{i 4}+\hat{\beta}_{\mathrm{SD}} \mathrm{X}_{i 5}+\hat{\beta}_{\mathrm{CHC}} \mathrm{X}_{i 6}+\hat{\beta}_{\mathrm{SRP}} \mathrm{X}_{i 7}+\hat{\beta}_{\mathrm{PLT}} \mathrm{X}_{i 8}
$$

where NDP: number of deceased parents, CD: cause of death due to AIDS,AI: average monthly income, LLS: lack of lovecare-support from care givers, SD: stigma and discrimination, $\mathrm{CH}$ : change in home circumstance, SRP: strength of relationship between parents before death, PLT: parent living together before death. Estimates of the regression parameters are listed in Table 2.

The odds ratios can be interpreted as follows.

The odds of being low self-esteem was decreased by $86.1 \%$ for a child who lost mother only and by $73.1 \%$ for that who lost father only as compared to that who lost both parents, other factors controlled. This indicates that an orphan who lost both parents is the most affected one. Losing father induces more risk of being low self-esteem than losing mother with difference as much as $13 \%$.

For orphan who knew that the cause of parents death was due to AIDS, the odds of developing low self-esteem was increased by $20 \%$ as compared to that whose parent death was due to non-AIDS causes. A unit increase in the average monthly income implies a decrease of odds of being low selfesteem by 0.993 . Economic status parents could positively affect child's self-esteem development. For a child who did not get expected love, care and support from care takers, the odds is 2.736 times that with better care. Similarly, stigma and discrimination increased the odds by 3.424 times; change in home circumstance increased the odds by 8.366 times; and weak relationship between parents before death increased the odds by 28.77 times.

Table 2. Results of Fitting the Final Model.

\begin{tabular}{|c|c|c|c|c|c|c|c|}
\hline Predictor & Category & $\hat{\beta}$ & $\operatorname{SE}(\hat{\beta})$ & Wald & d.f. & Sig. & $\operatorname{Exp}(\hat{\beta})$ \\
\hline \multirow[t]{2}{*}{ Constant } & & 3.525 & 1.20 & 8.67 & 1 & .003 & 33.96 \\
\hline & Both $(0)$ & - & - & 11.10 & 2 & .004 & \\
\hline \multirow[t]{2}{*}{ Deceased parents } & Mother (1) & -1.973 & .60 & 10.97 & 1 & .001 & .139 \\
\hline & Father (2) & -1.312 & .60 & 4.84 & 1 & .028 & .269 \\
\hline \multirow{2}{*}{ Cause of death due to AIDS } & No $(0)$ & - & - & & & & \\
\hline & Yes (1) & 0.182 & .71 & 0.07 & 1 & .001 & 1.20 \\
\hline Average monthly income & & -.007 & .001 & 30.99 & 1 & .000 & .993 \\
\hline \multirow{2}{*}{ Lack of love-care-support } & No $(0)$ & - & - & & & & \\
\hline & Yes (1) & 1.006 & .43 & 5.59 & 1 & .018 & 2.736 \\
\hline \multirow{2}{*}{ Stigma and discrimination } & No $(0)$ & - & - & & & & \\
\hline & Yes (1) & 1.231 & .50 & 6.08 & 1 & .014 & 3.424 \\
\hline \multirow{2}{*}{ Change in home circumstance } & No $(0)$ & - & - & & & & \\
\hline & Yes (1) & 2.124 & .40 & 27.68 & 1 & .000 & 8.366 \\
\hline \multirow{3}{*}{ Weak relationship between parents before death } & No $(0)$ & - & - & & & & \\
\hline & Yes (1) & 3.359 & .44 & 58.18 & 1 & .000 & 28.77 \\
\hline & Yes $(0)$ & - & - & 33.69 & 2 & .000 & \\
\hline \multirow[t]{2}{*}{ Parent living together before death } & Separated (1) & 0.055 & .61 & 0.01 & 1 & .000 & 1.056 \\
\hline & Divorced (2) & 0.392 & .66 & 0.35 & 1 & .267 & 1.480 \\
\hline
\end{tabular}

Synchronization of parents matters. Compared to a child from parents living together before death, the odds of being low self-esteem was increased by $5.6 \%$ for a child with separated parents and increased by $48 \%$ for that with divorced parents. Divorcing parents was found to be the biggest risk for the child to develop low self-esteem.

It is interesting thus to find that increased risk to low selfesteem was due to the factors: death of both parents, parent's death due to AIDS, low average monthly income, lack of love-care-support from care givers, stigma and discrimination, change in home circumstance, weak relationship between parents before death, and parent not living together before death.

\section{Conclusions}

The aim of the study was to identify risk factors that may affect self-esteem of orphans aged 5-18 years old. The results of the study revealed that prevalence of low self-esteem among the orphan was $57.3 \%$ which is quite high. 
From the logistic model analysis, eight risk factors were found to be significant at 5\% significance level. Increased odds of risk to low self-esteem was due to: parent not living together before death, weak relationship between parents before death, low average monthly income, death of both parents, death due to AIDS, change in home circumstance, lack of love-care-support from care givers, demonstrated stigma and discrimination.

In conclusion, a significant proportion of orphans are found to be of low self-esteem and so they deserve serious attention. The factors negatively affecting self-esteem of the orphans mainly include the unhealthy social life of parents. Parents should be aware about the consequences of decisions they make about their health and social life on their children's future self-esteem. Based on the identified risk factors, appropriate interventions need to be implemented to mitigate the challenges and so as to maintain normal selfesteem developments.

\section{References}

[1] Cluver LD, Gardner F (2008). Effects of Stigma on the Mental Health of Adolescents Orphaned by AIDS. Journal of Adolescents Health; 42: 410-417.

[2] Nyamukapa CA, Gregson S, Wambe M, Mushore P, Lopman B, Mupambireyi Z, Nhongo K, Jukes MCH (2010). Causes and Consequences of Psychological Distress among Orphans in Eastern Zimbabwe. AIDS Care: Psychological and Sociomedical Aspects of AIDS/HIV, 22: 8, 988-996.

[3] Smart R (2008). Policies for Orphans and Vulnerable Children: AFramework for Moving a Head. www.policyproject.com(accessed on September 2013).
[4] Xiaoming L (2008). Psychopathological Developmental Framework. Journal of the Association of Nurses in AIDS Care, 19(2): 147-157.

[5] Barber CN, Ball J, Armistead L (2003). Parent-adolescent relationship and Adolescent Psychological Functioning among African-American Female Adolescents: Self-esteem as a Mediator. Journal of Child and Family Studies, 12(3): 361374.

[6] Levine C, Foster G, Williamson J (2004). Children on the Brink. Joint Reports of New Orphans Estimate - A Frame Work for Action, New York, UNCIF.

[7] Baumeister RF, Campbell JD, Krueger JI, Vohs KD (2003). Does High Self-esteem Cause better Performance, Interpersonal Success, Happiness, or Healthier Lifestyles? Psychol. Sci. Public Interest, 4(1): 1-44.

[8] Rosenberg M, Owens TJ (2001). Low Self-esteem People. In Owens. T. J. Stryker, S, and Goodman (Eds) 2006. Extending Self-esteem Theory and Research, Cambridge. Cambridge University.

[9] Rosenberg M (1965). Society and the Adolescent Self-image. Princeton, NJ: Princeton University Press.

[10] Agresti A (1996). An Introduction to Categorical data Analysis. John Wiley Inc., New York.

[11] Hosmer DW, Lemeshow S (1989). Applied Logistic Regression. John Wiley and Sons. Inc. New York. 